\title{
As especificidades da apuração no processo de produção da reportagem
}

\author{
Paula Melani Rocha \& Mariana Galvão Noronha \\ Universidade Estadual de Ponta Grossa \\ E-mail: paulamelani@gmail.com/mariana.gnoronha@gmail.com
}

\begin{abstract}
RESUMO
$\mathrm{O}$ artigo propõe uma reflexão sobre o processo de produção de reportagem investigativa, com o propósito de aferir se há uma metodologia própria que perpassa por todo esse processo desde a seleção da pauta até a construção e veiculação. Traz um esforço em tentar definir o que seria essa metodologia conceitualmente, suas idiossincrasias. A discussão dialoga com autores que analisam $o$ jornalismo enquanto objeto de estudo, entre eles Otto Groth, Adelmo Genro Filho, Joaquim Fidalgo e Eduardo Me-

investigativo como um gênero, com especificidades tanto de forma quanto de conteúdo, o qual difere-se da cobertura factual e de atualidade. A discussão teórica fundamenta-se na teoria do interacionismo, em especial, newsmaking, percebendo o processo de produção do conteúdo jornalístico pela perspectiva da construção social. Os resultados apontam para um método de produção, constituído por determinados procedimentos articulados a uma apuração, porém com marcas de autoria.
\end{abstract} ditsch. Para isso, entende-se o jornalismo

Palavras-chave: jornalismo investigativo; produção jornalística; conhecimento em jornalismo; newsmaking; metodologia de apuração.

Data de submissão: 12-05-2016. Data de aprovação: 23-10-2016.

A Revista Estudos em Comunicação é financiada por Fundos FEDER através do Programa Operacional Factores de Competitividade - COMPETE e por Fundos Nacionais através da FCT - Fundação para a Ciência e a Tecnologia no âmbito do projeto Comunicação, Filosofia e Humanidades (LabCom.IFP) UID/CCI/00661/2013.

FCT COMPETE

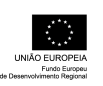

|l)点

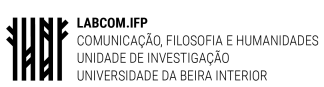




\title{
The specificities of research in the production of the investigative report
}

\begin{abstract}
The article proposes a reflection on the production process of investigative reporting, in order to assess whether there is a methodology that permeates throughout the hole process, from the selection of the subject to the construction and placement of the investigative report. Brings an effort to try to define what would it be this methodology conceptually, its idiosyncrasies. The discussion dialogues with authors who analyze journalism as an object of study, including Otto Groth, Adelmo Genro Filho, Joaquim Fidalgo

and Eduardo Meditsch. For this, the article Works withe the journalism investigativa as a genre, with specificities of both form and content, which differs from the factual coverage. The theoretical discussion is based on the interactionism theory, in particular newsmaking, realizing the production process of news content from the perspective of social construction. The results point to a production method, constituted of certain procedures articulated to a especific method, but with authorship marks.
\end{abstract}

Keywords: investigative journalism; journalistic production; journalism knowledge; newsmaking; research methodology.

\section{INTRODUÇÃO}

\begin{abstract}
A prática do jornalismo investigativo vem ganhando notoriedade não apenas no Brasil, mas também internacionalmente, sobretudo a partir do final do século XX. A queda de regimes não democráticos aliado a políticas de acesso a informação, internet, aplicativos e globalização favoreceram uma maior visibilidade e divulgação de conteúdo noticioso. Despontou-se uma tendência de favorecimento do exercício do jornalismo investigativo, simultaneamente a tecnologia e o modelo pós-industrial atingiram o modo de gestão em vigor até então do jornalismo e retraíram o staff das redações. Com estruturas mais enxutas, as empresas cortaram gastos, e o jornalismo investigativo, que é dispendioso, também foi atingido pelos cortes das redações brasileiras. No Brasil, entre os anos de 2011 e 2013, os grupos de comunicação do Paraná (rádio, TV, impressos) somaram 287 demissões. Em agosto de 2013, o Grupo Abril fechou quatro revistas. Na cidade de São Paulo, 280 demissões foram
\end{abstract}


homologadas de janeiro a abril de 2013, índice 37,9\% maior do que o mesmo período em 2012. ${ }^{1}$ Em 2015, segundo dados dos sindicatos dos Jornalistas dos estados de São Paulo e Paraná, o grupo Estado de São Paulo demitiu mais de 100 funcionários, o jornal Folha de S. Paulo demitiu quase 50, a TV Bandeirantes Litoral e o jornal Gazeta do Povo de Curitiba também demitiram 11 jornalistas cada um (Rocha, 2016). Ao todo, em 2015 foram computadas mais de 1400 demissões de jornalistas no país. Apesar de abalado dentro das redações, o jornalismo investigativo encontrou oportunidades fora delas, em iniciativas colaborativas, ONGs, coletivos, apoio de fundações e projetos independentes, além de ainda manter um espaço simbólico em alguns veículos nacionais. Por sua relevância social e interesse público, as reportagens investigativas são essenciais para os regimes democráticos e utilitárias para a transformação e denúncias em regimes não democráticos.

A reflexão proposta versa sobre a prática do jornalismo investigativo, busca-se aferir se há ou não uma metodologia própria que atravessa todo o processo de produção e se pode inclusive ser denominado como metodologia. É válido ressaltar que o método de apuração em discussão não é sinônimo de método científico, pois entende este último como um conceito acompanhado de pelo menos uma fundamentação teórica (Mendras, 1975, p.14). Porém, como será exposto na discussão, entende-se que a apuração jornalística investigativa pode em determinado momento utilizar-se de método científico, ao apropriar-se do Jornalismo de precisão, o qual de acordo com Meyer (1973, 1991), faz uso de métodos científicos das investigações sociais e psicossociais, principalmente no campo das ciências sociais, para coletar e analisar dados em reportagens investigativas. Também denominado como Reportagem com Auxílio de Computador (RAC).

A discussão faz parte da pesquisa "As especificidades do Jornalismo Investigativo - um estudo sobre a metodologia do processo de produção jornalística investigativa", desenvolvida junto ao Programa de Pós-graduação Mestrado em Jornalismo da Universidade Estadual de Ponta Grossa (UEPG). Utilizou-se de pesquisa bibliográfica para fundamentar os conceitos apresentados: jornalismo investigativo, processo de produção jornalística, conhecimento em jornalismo, metodologia, apuração jornalística e newsmaking.

1. Dados da reportagem "A revolta dos passaralhos", considerando apenas jornalistas registrados. www.apublica.org/2013/06/revoada-dos-passaralhos 
Optou-se por uma abordagem qualitativa considerando o levantamento e interpretação de dados. Nesse primeiro momento, cruzou-se pesquisa bibliográfica e documental, análise de reportagens investigativas e entrevista com profissionais que atuam em jornalismo investigativo. O percurso bibliográfico é o que permite identificar não somente os avanços desse gênero jornalístico, mas também os marcos em seu desenvolvimento e constituição nas especificidades que hoje permeiam esse processo de produção específico, como a diferenciação no método de apuração e nos temas das reportagens, que normalmente trazem irregularidades político-administrativas, tanto de governo quanto de outras autoridades (Nascimento, 2010).

A estrutura do artigo contempla três etapas de discussão interligadas na construção da reflexão proposta com o propósito de identificar se há uma metodologia própria no processo de produção da reportagem investigativa e tentar classificá-la. A primeira etapa justifica-se por apontar os atributos em contemplar o jornalismo pela suas especificidades na tentativa de compreender sua complexidade e idiossincrasias. A segunda parte traz referências bibliográficas que mencionam o mesmo objeto proposto aqui: jornalismo investigativo e apuração investigativa. Nesse sentido, apresenta o jornalismo investigativo como um gênero jornalístico, com características próprias e em transformação. Assim, ela é o aporte que sustenta o caminho a ser percorrido pela análise pontuada na terceira parte do texto, a qual versa sobre o processo de produção da reportagem investigativa, desde a seleção da pauta, o que a constitui e todo o percurso de produção da reportagem, pela perspectiva do newsmaking, procurando observar suas marcas, diferenciais, interações, repetições na busca de apreensão do objeto investigado. Para isso, considera-se tanto a discussão teórico conceitual quanto depoimentos de jornalistas investigativos proferidos no $10^{\circ}$ Congresso Internacional de Jornalismo Investigativo promovido pela ABRAJI (Associação Brasileira de Jornalismo Investigativo), em São Paulo, no período de 2 a 4 de julho de 2015, bem como documentos publicados por associações internacionais de jornalismo investigativo, mencionadas ao longo do texto. ${ }^{2}$

2. Entre os documentos analisados estão: Manual de verificação. Um guia definitivo para verificação de conteúdo digital na cobertura de emergências Disponível em www.verificationhandbook.com/book_br/index.php; e A investigação a partir de histórias. Um manual para jornalistas investigativos. Disponível em http://unesdoc.unesco.org/images /0022/002264/226456POR.pdf. 


\section{O JORNALISMO COMO OBJETO DE PESQUISA}

Um dos autores a discutir o Jornalismo como ciência, considerando objeto de pesquisa e metodologia, foi Groth (2011) pela perspectiva da Ciência dos Jornais, que iniciou no fim do século XIX na Alemanha, país que apresentou pioneirismo acadêmico no Jornalismo. Na obra, Groth (2011, p.29) apresenta um panorama do surgimento da disciplina na Alemanha, defendendo que "novas ciências especificas, nascem, via de regra, das necessidades, da urgência da vida". O autor expõe que a Ciência dos Jornais precisou então buscar por um espaço de reconhecimento entre as ciências já instituídas.

O primeiro passo para a conquista de um objeto próprio é, como dissemos, o destacamento do seu conteúdo do todo natural e sociocultural, o isolamento de determinadas manifestações iguais ou isoladas - no nosso caso, jornais e revistas - e a sua condensação em um grupo especial (...) Primeiro, cada ciência tem que comprovar, ter um "objeto próprio" que as outras ciências até agora não analisaram e cuja análise as intenções destas ciências também não permitem. Este modo especial de contemplação e elaboração de um objeto nos proporciona um conhecimento específico do objeto, que é ordenado segundo princípios específicos de classificação. Isto quer dizer que este conhecimento tem que ser colocado em um "sistema" e só então a nova ciência está fundada, só então ela pode reivindicar o reconhecimento de sua autonomia (Groth, 2011 p. 32).

O autor trata da Ciência dos Jornais para defender que o jornalismo deve ser analisado sob uma perspectiva particular, um olhar ainda não adotado nas metodologias desenvolvidas por outras ciências. Isso porque o jornalismo tem seu próprio objeto de pesquisa, o produto jornalístico, o qual apresenta uma complexidade de características e categorias próprias como universalidade, periodicidade, atualidade e difusão (Groth, 2011), aplicáveis a diferentes veículos (Genro Filho, 1987) sejam revistas, jornais ou mesmo outras plataformas.

Oliveira (2014) dá destaque à pesquisa da essência, defendida por Groth, afirmando que "a primeira tarefa da disciplina teórico-sistemática é submeterse à pesquisa da essência, se quiser enfim ser reconhecida como ciência" (Oliveira, 2014, p.07). 
Ao investigar a essência do objeto da Ciência dos Jornais, nós nos deparamos primeiro com a periodicidade como a característica manifesta e, portanto, imediatamente saliente e incondicionalmente evidente. Ao infiltrarmo-nos no conteúdo dos objetos, nós reconhecemos as características da universalidade e nela contida atualidade, e por fim identificamos a qualidade da publicidade, que nos dá a direção, o objetivo da obra e com isso nos conduz ao seu sentido (Groth, 2011, p. 144).

Com relação ao método, Coelho Sobrinho (2013) pondera que embora Groth (2011) tenha criticado a falta de um método científico específico à ciência dos jornais para apreensão do objeto científico, Genro Filho (1987) se propõe a resolver esta questão ao distinguir o objeto teórico do objeto real.

Ao primeiro dá o sentido do conhecimento, da essência do saber, e ao segundo associa a forma de manifestação bruta, reduzindoo ao suporte sensível e concreto do jornalismo. Portanto, Genro Filho faz uma distinção entre a natureza e a forma do jornalismo, dando ao objeto teórico a capacidade de oferecer e acumular conhecimentos vinculados aos princípios jornalísticos e atribuindo ao objeto real o sentido de fragmento do fenômeno (Coelho Sobrinho, 2014, p. 139).

O jornalismo tem uma forma de conhecimento de direito próprio. Não é apenas um instrumento para transmitir conhecimentos produzidos por outrem e nem tão somente um meio de comunicação, mas é também um meio de conhecimento com relevância e responsabilidade do seu papel social (Meditsch, 2002). Dessa forma, Coelho Sobrinho (2014, p.140) direciona a discussão sobre a prática do jornalismo, ao demonstrar que o fazer jornalístico "tem um campo nitidamente delimitado, apesar de amplo". Em consonância, Sponholz (2009) caracteriza o jornalismo como um tipo de processo de conhecimento envolvendo os seus produtores e receptores. No entanto, segundo a autora, os jornalistas precisam trabalhar o conteúdo que produz de forma crítica e com responsabilidade social, o que demanda uma concepção teórica de conhecimento que possibilite aos profissionais conhecer a realidade, lembrando que "o conhecimento total da realidade continua sendo uma utopia, a busca deste é, no entanto, o que nos leva a ir adiante" (Sponholz, 2009, p.13). Pode-se 
considerar aqui que o processo de produção jornalística demanda um conhecimento ao transformar um fato em acontecimento jornalístico. Para Fidalgo (2008, p.11) jornalismo é uma profissão que exige um saber complexo com dimensões reflexivas, o qual denomina como "saber profissional". São diferentes saberes adquiridos a partir do conhecimento formal e do exercício da prática.

(...) um tipo de trabalho "técnico-intelectual", que vai para além de uma mera lógica "técnico-instrumental" (Caria, 2005 p.198). E isto por três motivos essenciais: (1) nesta acção profissional estão inscritos também "valores e orientações morais" que fazem com que os critérios de interação com "o outro" não sejam desvalorizados; (2) os conhecimentos mobilizados não são uma mera aplicação da ciência adquirida em educação formal prévia e, pelo contrário, obrigam a "operações sócio-cognitivas de recontextualização profissional do conhecimento"; e (3) a autonomia no contexto de trabalho implica o "desenvolvimento de uma reflexividade profissional própria" que saiba lidar com a incerteza e a singularidade das situações (Fidalgo, 2008, p.14).

Assim, associa-se à teoria do construcionismo, pela perspectiva do newsmaking, na medida em que o processo de produção do conteúdo, desde a seleção, apuração, construção e veiculação envolve uma série de escolhas, procedimentos, atores sociais, tensionamentos, pressão do tempo, atuação da estrutura organizacional, cultura profissional e cabe ao jornalista conduzir este processo com conhecimento e competência profissional para que o processo se concretize com eficiência. $\mathrm{O}$ jornalismo não deslumbra um trabalho técnico, mecânico e meramente reprodutivo. O conhecimento reproduzido perpassa pela administração das informações contidas nos fatos jornalísticos, que são determinados por padrões, valores morais, epistemológicos e deontológicos da profissão.

O jornalista trabalha com a divulgação de fatos de informações, as quais, de acordo com Chaparro (2001, p.41), devem produzir "alterações significativas na realidade presente das pessoas". Para o autor, caracteriza-se uma reação em cadeia, na qual os atos comunicativos do jornalismo desencadeiam comportamentos e as ações sociais realimentando "(...) o processo social, provocando transformações nos cenários da atualidade e da ordenação ética e 
moral da sociedade"(Chaparro, 1994, p.30 30). E os fatos jornalísticos também não são isolados, fragmentos sociais que encerram em sim mesmos, eles fazem parte de uma continuidade de ações e movimentos da sociedade. Como coloca Genro Filho (1987, p.186-188):

Os fatos jornalísticos são um recorte do fluxo contínuo, uma parte que, em certa medida, é separada arbitrariamente do todo. (...) A verdade se resume a um processo de revelação e constituição do fato exposto pelo jornalista, isto é o fato deve ser entendido na sua forma polissêmica por se tratar de uma versão traduzida com o poder de valores e interesses.

Assim, o jornalismo é uma atividade intelectual em que toda ação exige um pensar, um aprender e um inovar. Pode-se dizer que cada cobertura mobiliza determinadas capacidades reflexivas na busca de respostas necessárias para o contexto da ação. Nesse sentido, a competência profissional não caracteriza-se somente pela ação, mas por uma ação reflexiva, a qual sustenta os "saberes de ação", caracterizados por Schön (1996, apud Fidalgo, 2008) como "uma nova epistemologia do agir profissional". Como pontua Fidalgo (2008), as competências jornalísticas demandam um saber prático, o qual congrega o "saber conhecer", "saber fazer" e "saber-ser".

Aqui estabelece-se constantemente uma relação com a experiência, com o trabalho concreto e com a aprendizagem que (também) se realiza nele e através dele, num processo que não significa mera justaposição de saberes, mas o seu relacionamento dialético (Fidalgo, 2008, p. 9).

A ação e a reflexão sobre ela gera novos saberes. Ao pensar nas coberturas jornalísticas concebe-se assim que os "saberes de ação"vislumbrados nas reportagens investigativas não são os mesmos aplicados em uma cobertura diária. Ettema e Glasser (1984), apontam que no seu estudo sobre as rotinas do jornalismo, Tchuman ao discutir sobre a tipificação da "programação", referente a como um evento será tratado, o "head news"é qualificado como jornalismo investigativo. O tópico seguinte discute pontualmente as especificidades da reportagem investigativa e parte da prerrogativa que os procedimentos empregados no processo de produção caracterizam sobretudo um movimento contínuo de apuração. A discussão trata esses procedimentos como 
uma metodologia de apuração, porém é válido mencionar que não se trata de um método científico, já descartado pela ciência dos jornais, mas sim um método que constitui também o "saber profissional".

\section{O JORNALISMO INVESTIGATIVO E SUAS DELIMITAÇÕES: BUSCA DO MÉTODO DE APURAÇÃo}

Pensar o jornalismo investigativo pela perspectiva do método não é pioneirismo desta reflexão. O próprio documento $A$ investigação a partir de histórias. Um manual para jornalistas investigativo publicado em 2013, pela UNESCO, traz os métodos e as técnicas do jornalismo investigativo, sem se limitar à busca de informações ou de como encontrá-las, mas por um viés holístico envolvendo todo o processo de produção da reportagem investigativa.

Não pensamos que a questão básica seja como encontrar informações. Ao invés disso, pensamos que a tarefa central é como contar uma história. Isso nos leva à inovação metodológica básica deste manual: Usamos as histórias como o cimento que mantém a coesão entre cada passo do processo investigativo, desde a concepção até a pesquisa, redação, controle de qualidade e publicação. Também nos referimos a essa abordagem como a investigação a partir de histórias, porque começamos formulando a história que esperamos redigir como uma hipótese que será ou verificada ou refutada. Esse é o primeiro passo em um processo integrado (Hunter et. al., 2013, p.4).

Nesse sentido, o ponto inicial é o fato que será narrado, ou seja a pauta a ser investigada. É a pauta que define o método investigativo. Porém, para os autores todas as pautas partem do pressuposto de uma hipótese para a história, estratégia já utilizada por empresas de consultoria, pelas ciências sociais e pelas investigações policiais. A partir da hipótese são desenhados os seguintes passos (Hunter et. al., 2013, p.5):

- o repórter consegue visualizar as informações que necessita buscar;

— o profissional de edição pode "avaliar mais facilmente a factibilidade, os custos, as recompensas e o avanço"do projeto investigativo; 
- já durante o processo de produção, os profissionais envolvidos organizam o material coletado para a redação e começam a construir partes específicas do texto final;

- esse procedimento auxilia no controle e permite uma visão "mais perspicaz sobre o quão bem a história atende a critérios legais e ético";

- o resultado é uma história "que pode ser resumida em algumas poucas frases de impacto - uma história que possa ser promovida, defendida e lembrada"(Hunter et. al., 2013, p.4).

Percebe-se, assim, que o processo de produção e construção do conteúdo informativo não caracteriza-se por um movimento linear e sim pendular, mesclando de forma contínua, porém finita, apuração, redação do texto e verificação. É válido mencionar, como os próprios autores colocam, que essas constatações sobre um procedimento metodológico não são embrionárias e sim fruto de estudos e observações práticas por um conjunto de profissionais. Em 1990, a tese de Mark Lee Hunter trouxe uma comparação entre os métodos investigativos franceses e norte-americanos. Posteriormente, durante 12 anos, Hunter trabalhou no Instituto Francês de Imprensa da Universidade de Paris/Panthéon-Assas, e junto com os colegas testou na prática os métodos apontados no manual para jornalistas investigativos (Hunter et. al., 2013).

Juntamente com alguns colegas, entre eles Yves Doz, Luk Van Wassenhove, Ludo Van der Hayden e Kevin Kaiser, refletiram sobre as práticas e processos no campo do jornalismo. Em 2001, com o surgimento da Rede Global de Jornalismo Investigativo, motivada por uma rede de membros de diferentes entidades como do Instituto Dinamarquês para a Cobertura Jornalística Auxiliada por Computador e do Repórteres e Editores Investigativos Inc., criou-se um fórum "para o intercâmbio de boas práticas"(Hunter et. al., 2013, p.5). Contudo, como o próprio autor coloca, esse movimento de observar os elementos de investigação a partir das histórias eclodiu em diferentes lugares, como Holanda e Dinamarca.

Já na década de 1970, o jornalista americano Philip Meyer, ao defender o Jornalismo de Precisão, referia-se à aplicação de métodos científicos das ciências sociais para levantar e analisar dados, em movimento contrário ao New Jornalism impulsionado a partir da década de 1960.

O jornalismo de precisão foi uma forma de expandir o arsenal de ferramentas do repórter para tornar temas antes inacessíveis, ou 
parcialmente acessíveis, em objeto de exame minucioso. Foi especialmente eficiente para dar voz à minoria e grupos dissidentes que estavam lutando para se verem representados (Meyer, 1993, p.15).

Antes mesmo de Philip Meyer utilizar dados na reportagem sobre as manifestações em Detroit para mostrar que os participantes não eram pessoas de baixa escolaridade da região sul, em 1952 a TV americana CBS usou-se de análise de dados para prever o resultado das eleições presidenciáveis. Iniciava uma nova forma de fazer jornalismo, na década de 1960, jornalistas, sobretudo nos Estados Unidos, passaram a visitar bases de dados públicas com métodos científicos para fiscalizar o poder de forma independente. Denominado de Jornalismo de interesse público, os defensores das técnicas baseadas no auxílio do computador procuram revelar tendências, contrariar o senso comum e desnudar injustiças perpetradas por autoridades e corporações (Gray, et. al., 2012)

Nos anos de 1980, a pesquisadora Quesada (1987 apud Sequeira 2005, p.74) defende que a diferenciação do jornalismo de atualidade e o jornalismo investigativo não está no formato do texto ou na apresentação gráfica do material, mas está justamente no processo de trabalho do profissional, mais especificamente, as estratégias que ele usa para a apuração do material.

O simples fato de um texto jornalístico conter cifras, estatísticas, porcentagens econômicas, documentação e declarações não o define como jornalismo investigativo, já que todas essas informações podem ser obtidas de uma fonte oficial, extraída de documentação ou entregue em forma de press-release. "Só no momento em que o repórter passa a utilizar técnicas e estratégias que não fazem parte das rotinas dos trabalhos jornalísticos de atualidade a reportagem se transforma em reportagem investigativa" (Sequeira, 2005, p.74).

A brasileira Sequeira (2005) mostra que o jornalismo investigativo demanda métodos de pesquisa e estratégias operacionais. Lopes e Proença (2003, p. 10) seguem a mesma lógica ao defenderem que no jornalismo investigativo o levantamento de informação é algo susceptível de ser "trabalhado mais a fundo, de ser documentado, ampliado, verificado, contextualizado, indagado e investigado sob todos os ângulos". 
Sobre as técnicas e passos que permeiam o processo de produção e que se caracterizam como uma metodologia da reportagem investigativa, o jornalista Fortes (2005) menciona o uso das fontes, entrevistas, levantamento de dados e documentação, porém há uma alternância no compasso da sequência das etapas do processo de investigação jornalística, já que o jornalismo investigativo depende do cruzamento das informações obtidas por meio de todas essas estratégias.

Uma boa investigação é demorada e, normalmente, recheada de documentos, dados, estatísticas, legislações e códigos de onde se tira o extrato necessário para a notícia. Muitas vezes, não é de uma fonte ou de um documento que se obtém a informação, mas do cruzamento de vários deles. Os dados estatísticos devem ser lidos com cuidado, pois escondem tratamentos técnicos e avaliações que passam despercebidos pelos leigos (Fortes, 2005, p.31).

Ao analisar o jornalismo investigativo na web, na sua dissertação Martins (2011) aborda o processo de produção e traz procedimentos como pesquisa documental, fontes consistentes, planejamento do espaço, relevância do tema, técnicas de apuração (câmera escondida e prática de infiltração). O interessante é que a autora também traz o aspecto da autoria na escolha dos procedimentos adotados no processo de produção da reportagem.

O uso de procedimentos de apuração diferenciados no processo de produção de reportagens investigativas datam de iniciativas notórias como a de Ida Tarbell na série de reportagens The History of Standard Oil Co publicadas entre 1902 e 1904 na revista americana McClure's Magazine, em que denunciou práticas ilícitas das empresas de John Rockfeller, durante anos facilitando a instalação e hegemonia das empresas no território nacional. O trabalhou de apuração iniciou em 1900 com o levantamento de documentação oficial envolvendo irregularidades nos acordos firmados entre a empresa e o governo, entrevistas com magnatas do petróleo, funcionários das empresas de petróleo e especialistas. Uma investigação minuciosa e morosa.

Na década de 1950, o jornalista argentino Rodolfo Wash com a investigação que resultou na obra Operação Massacre, é outro exemplo que merece ser mencionado por suas particularidades na apuração. Ao deparar-se com um sobrevivente de um possível fuzilamento clandestino realizado pela polícia argentina em junho de 1956, contra 12 pessoas, o jornalista vai atrás da 
recomposição dos fatos. Ele busca os outros sobreviventes, seus familiares, volta à cena do episódio, entrevista moradores e também policiais. O trabalho é incessante. Durante décadas o jornalista investiga o ocorrido e amplia a apuração para as irregularidades que o governo praticou contra peronistas e durante a ditadura no país. Rodolfo Wash articula acontecimentos em momentos diferentes, investiga os pareceres judiciais, cruza informações e confronta dados. O jornalista desenvolveu métodos de apuração e checagem de informações precisos e elaborados. O livro Operação Massacre foi publicado com três edições diferentes, ao longo de 20 anos, acrescentando prólogos e notas de atualização numa busca incansável de dados sobre a ditadura argentina (Walsh, 2010). Os dois exemplos ilustram as especificidades adotadas por cada profissional durante o processo de produção da investigação jornalística.

Percebe-se procedimentos similares como levantamento e leitura de documentos, realização de entrevistas com fontes primárias e secundárias, não limitam-se a fontes oficiais, pelo contrário, buscam ouvir uma pluralidade de fontes, confrontam dados, e foram publicados de forma diferenciada, a princípio em séries, contudo isso só é conhecido porque ambos os trabalhos estão publicados em livro, os quais detalham o esforço e os movimentos realizados pelos jornalistas. Portanto, a análise não pode fundamentar-se apenas pelo produto, reportagem publicada. Como mostrou anteriormente a produção jornalística é processual e a apuração está presente em grande parte das etapas, caracteriza-se um movimento de idas e vindas, de escolhas e decisões, a entrevista com o repórter é essencial para tomar ciência desse processo e conseguir identificar suas marcas.

Assim, ao buscar identificar a metodologia da produção e construção de reportagens investigativas, com o propósito de aferir os procedimentos e técnicas que a constituem e suas peculiaridades, vislumbrou a necessidade em ouvir os profissionais que trabalham nesse tipo de cobertura pela necessidade em entender o processo. Ao ouvir os profissionais acredita-se que irão auxiliar na verificação das técnicas possíveis, suas articulações, razões de escolha ao longo das etapas que envolvem todo o processo da reportagem investigativa, desde a seleção da pauta, apuração e produção das informações bem como a construção do texto investigativo para veiculação, para identificar se há um protocolo padrão, ou não e o que determina as escolhas dos procedimentos de investigação. A reflexão parte do pressuposto de que esse processo é en- 
volvido por técnicas e procedimentos diferentes dos que são tradicionalmente usados no jornalismo diário.

\section{A AUTORIA E O PROCESSO DE PRODUÇÃO DA REPORTAGEM INVESTI- GATIVA}

Para a análise das reportagens foram pensadas categorias com o intuito de identificar se o conteúdo realmente se enquadra nos moldes de reportagem investigativa, que caracteriza-se principalmente pelo protagonismo do repórter na descoberta de um fato e informações até então não divulgados (Rosenstiel e Kovach, 2004), a pauta é resultado do trabalho de investigação do repórter e não de outra instituição, como Ministério Público ou Polícia Federal. Escavar um tema até então submerso é uma característica determinante na investigação jornalística. Em seguida partiu-se das seguintes variáveis: a classificação das fontes em 'categoria', 'grupo' e 'critério', identificando nas reportagens investigativas quais as fontes primárias e secundárias, empresariais ou especialistas, como forma de perceber pluralidade de fontes nas reportagens investigativas; os critérios de noticiabilidade que determinam a cobertura, denúncia e políticas públicas; e uso de recursos como infográficos e imagens. A análise das reportagens contribuiu também para identificar nos textos outras especificidades do gênero investigativo, que não foram mapeadas durante o levantamento bibliográfico, além de revelar aspectos de regularidade no processo produtivo.

A classificação das fontes segue a proposta de Schmitz (2011): categoria, grupo e crédito. $\mathrm{Na}$ 'categoria', as fontes dividem-se entre primárias e secundárias. São primárias aquelas fontes que estão diretamente envolvidas aos fatos, que fornecem a essência da reportagem. As fontes secundárias são aquelas que contextualizam e complementam as informações que foram apresentadas pelas fontes primárias. Há uma adaptação na classificação das fontes no que se refere à categoria. Devido a complexidade de informações nas reportagens investigativas, foi acrescentada a definição de importância que Pereira Junior (2006) dá aos personagens do acontecimento jornalístico. As fontes primárias foram divididas naquelas que são fulcrais, cuja reportagem não existe sem elas, e as primárias de média importância.

A classificação 'grupo', também segue a divisão de Schmitz (2011). Por fonte oficial, entende-se alguém em função ou cargo público e se pronuncia por órgãos do Estado. Como empresarial, compreende aquela fonte que repre- 
senta corporação empresarial, seja indústria, comércio ou serviços. Institucional é aquela fonte que responde por uma organização sem fins lucrativos ou grupo social. A fonte popular é aquela que aparece como vítima de determinada situação, que fala por si mesma, diferente da fonte testemunhal, que fala sobre o que viu acontecer com outro. A fonte especializada é aquela que apresenta um saber específico ou reconhecido, geralmente relacionada a alguma profissão ou área de atuação. A fonte referencial é definida como qualquer bibliografia ou documentos que são usados na constituição da reportagem.

Quanto ao 'crédito', o artigo usa a classificação de Sousa (2001), que divide as fontes da reportagem em on the record, on background, on deep background e off the record. Isso porque as reportagens investigativas contam com uma variedade de fontes maior que a classificação entre 'identificada' ou 'anônima'.

On the record (atribuição directa, para publicação) - A fonte é identificada e tudo o que ela profere pode ser objeto de enunciação jornalística. É a regra comum e aquela que deve ser usada quando a fonte não pede confidencialidade. On Background/not for attribution (atribuição com reserva) - A fonte não é totalmente identificada, embora sejam dadas algumas pistas superficiais sobre os meios em que ela se movimenta. [...] On deep background (atribuição com reserva total) - Não só a fonte não é identificada como também não pode ser referido o meio em que ela se movimenta, embora as informações fornecidas pela fonte possam ser difundidas. [...] Off the record (confidência total) - A fonte não pode ser identificada e a informação que ela fornece não pode ser divulgada. Contudo, esta informação auxilia, frequentemente, o trabalho do jornalista (Sousa, 2001, p. 67-68).

De certa maneira, o caminho metodológico do jornalismo investigativo é seguir os dados, cruzá-los e interpretá-los. As fontes humanas, primárias ou secundárias, são usada apenas como uma das técnicas e não a única, para confirmação das informações levantadas em bancos de dados ou documentos oficiais. O jornalismo factual diário costuma limitar-se às informações e dados repassados pelas fontes humanas, em geral oficiais ou especialistas. Entretanto, devido às temáticas, bem como a profundidade e complexidade dos assuntos pautados nas reportagens investigativas, a apuração que não cruza as 
informações obtidas pode ficar superficial, rasa e até mesmo incompleta. E a publicização da informação incorreta causa um dano irreparável aos envolvidos.

Para esta publicação, foram selecionadas para análise quatro reportagens premiadas da Agência Pública ${ }^{3}$, de autoria feminina, publicadas no período de 28/08/13 a 29/05/14. Nesta análise, constatou-se o uso de 63 fontes, sendo 18 primária fulcral, 15 primária média importância e 30 secundárias. Com relação à classificação por grupo o resultado foi:

\begin{tabular}{lc} 
Grupo & Número de fontes \\
\hline Oficial & 17 \\
Institucional & 10 \\
Popular & 8 \\
Especializada & 12 \\
Referencial & 8 \\
Testemunhal & 5 \\
Empresarial & 3 \\
\hline Total & 63 \\
\hline
\end{tabular}

Tabela 2. Atores com maior grau de intermediação no recorte.

As reportagens são extensas, variando entre 11 mil e 55 mil caracteres. $\mathrm{O}$ tamanho dos textos representa um aumento proporcional no número de fontes. Na reportagem Dor em Dobro, por exemplo, o texto com 55 mil caracteres é construído com base em 25 fontes identificadas; em Severinas: as novas mulheres do Sertão são 10 fontes em um texto com 11 mil caracteres; Em Guerra Contra a Nestlé constam 15 fontes em uma reportagem com 28 mil caracteres; e Quanto mais presos maior o lucro conta com 19 mil caracteres, embasada em 13 fontes identificadas.

Entretanto, a quantidade de fontes não necessariamente implica em pluralidade ou profundidade da informação. Com exceção da maior reportagem analisada todos os textos apresentam número maior ou igual entre fontes primárias fulcrais e as de média importância. Na reportagem em questão, com 25 fontes, somente duas dela são fulcrais, sendo seis de média importância e

3. http://apublica.org/2014/05/dor-em-dobro-2/; http://apublica.org/2013/08/severinas-n ovas-mulheres-sertao/; http://apublica.org/2014/04/em-guerra-contra-a-nestle/; http://apublic a.org/2014/05/quanto-mais-presos-maior-o-lucro/. 
17 fontes secundárias de contextualização. Nenhuma outra reportagem apresenta número de fontes secundárias superior ao número de fontes primárias (fulcrais e média importância).

A análise ainda revelou que, na classificação por grupo, as fontes que mais se sobreassem são as oficiais, institucionais, especializadas, testemunhais e populares, nessa sequência. Em entrevista ${ }^{4}$, a jornalista Marina Almeida que fez a reportagem "Em guerra contra a Nestlé"informou que fez cerca de 30 entrevistas, entre elas estavam conversas com moradores e frequentadores do parque que não acompanhavam a questão das águas, "mas não aproveitei as entrevistas porque não acrescentaram muito - alguns concordavam que o parque já foi melhor, outros não sabiam responder, não tinham notado... ". Ela também descartou a entrevista de vereador e de um funcionário da secretaria de Turismo, "porque não acrescentavam nada às outras entrevistas citadas na matéria. O critério foi esse: o que as entrevistas tinham a acrescentar à discussão".

Quanto aos procedimentos de apuração, Marina Almeida utilizou levantamento e análise documental, fontes secundárias, fontes primárias, entrevistas, observação in loco, cruzamento e interpretação de dados e checagem e rechecagem sobretudo das questões mais técnicas. Sobre o processo de apuração, ela discorre como percorreu as etapas:

(...) primeiramente li as notícias que encontrei sobre as águas de São Lourenço, uma tese sobre o movimento de 2000 que também dava um bom histórico da região e das discussões sobre a superexploração e fiz algumas pré entrevistas por telefone. Em novembro passei uma semana na cidade entrevistando os moradores, políticos, Ministério Público, entre outros. Visitei o parque algumas vezes e tinha conseguido agendar uma visita guiada à fábrica, que foi desmarcada. Também fui à cidade de Cambuquira que tem um grupo forte de defesa das águas. Já em São Paulo fiz outras entrevistas por telefone, com o movimento de Caxambu que não pôde me receber em novembro, deputado mineiro, Ministério Público da área cultural de Minas, que fica em BH, entre outros. Tentei por diversas vezes uma entrevista com o DNPM nacional, sem sucesso, mas levantei alguns dados por meio da

4. Entrevista realizada por email em 02/06/2015. 
lei de acesso à informação e falei com um funcionário do CPRM mineiro, por telefone. Nessa fase, analisei vários documentos dos processos, atas de reuniões, teses, estudos sobre as águas da região etc. Entrevistei pesquisadores sobre hidrogeologia, formação da água mineral, etc. Para entender e traduzir melhor alguns termos técnicos utilizei alguns manuais, como o Manual de Construção de Poços Tubulares. Depois de todo esse processo, redigi a matéria.

O relato da jornalista Arbex (2012) sobre sua investigação do Caso Koji (uma empreiteira de Juiz de Fora (MG)) mostra bem a importância de cruzar as informações obtidas por meio dessa metodologia de apuração para garantir o material final mais confiável. A pauta chegou até ela em abril de 2008, numa conversa informal com um motorista de táxi. Quando o taxista comenta sobre o andamento da política em Juiz de Fora, afirmando que até vereador é dono de construtora, ela se interessa em levantar a história. "Nunca tinha ouvido falar sobre a Koji e nem que a tal empresa pudesse pertencer a um dos políticos mais influentes da região: Vicente de Paula Oliveira, presidente da Câmara Municipal há 20 anos no poder" (Arbex, 2012, p. 171).

Numa pesquisa superficial, Arbex identifica o nome da empreiteira em licitações da Prefeitura de Juiz de Fora. Os Atos do Governo, documento oficial, indicavam que a empresa havia ganho licitações em todas as secretarias municipais entre os anos de 2005 e 2008, mesmo período em que o referido vereador estava à frente da Câmara Municipal. Apesar da conexão imediata, a jornalista reconhece que a prova era muito fraca para a divulgação em reportagem. A partir disso, inicia-se um longo processo de verificação de documentos e confirmação do esquema de forma inegável. A primeira medida foi procurar provas na Junta Comercial do Estado de Minas Gerais, em busca dos sócios da construtora, uma consulta que pode ser realizada por qualquer cidadão, pois tratam-se de informações públicas (Arbex, 2012).

Com o nome de sete sócios em mãos, a autora parte para o Ministério do Trabalho e descobre que os sócios tinham baixa qualificação profissional, ocupando cargos como auxiliares e vigilantes. Apesar de identificar quem seriam os 'laranjas' no esquema, a apuração ainda não havia identificado o elo entre o vereador e a construtora. Foi numa consulta à Justiça do Trabalho que a jornalista encontrou um processo trabalhista contra o vereador, que nomeou 
no processo uma mulher como sua preposta. O nome em questão era tanto da secretária executiva na presidência da Câmara Municipal como também secretária executiva da empreiteira Koji. A partir daí, com outras consultas e acesso a novos documentos, todos eles públicos, a jornalista consegue provar a ligação existente entre o vereador, sua construtora e as licitações ganhas na Prefeitura. Foi somente com todo esse material em mãos que a jornalista saiu a campo, para entrevistar os envolvidos no esquema (Arbex, 2012).

A conversa, inicialmente amistosa, foi ficando tensa, na medida em que Vicentão foi percebendo a qualidade das provas que tínhamos em mãos. Num dos momentos mais delicados, o fotógrafo Fernando Priamo conseguiu flagrar o instante em que Vicentão apontou o dedo indicador para nós, simulando uma arma. Ameaça clara, flagrada por Priamo num competente trabalho de equipe (Arbex, 2012, p.174).

Marina Almeida também comenta o acesso às fontes envolvidas, após ter coletado as informações e a reação não receptiva em atender a imprensa. Contudo, ela recorreu à lei de acesso à informação para obter os dados:

A maior dificuldade foi para entrevistar a Nestlé, que só respondeu a algumas perguntas por e-mail e não respondeu a algumas questões alegando sigilo comercial, cancelou a visita à fábrica e também não divulgou um estudo que realizou na região. Também foi difícil conversar com os deputados envolvidos na comissão do novo Código de Mineração, apenas o presidente da Comissão falou comigo. O DNPM também não colaborou com entrevistas, apesar das inúmeras tentativas, e só respondeu às questões enviadas pela Lei de Acesso à Informação.

A documentação é crucial no jornalismo investigativo, principalmente quando são utilizadas fontes off the record. Esse levantamento documental dos antecedentes do fato em questão serão a base da estratégia do restante do processo de apuração, permitindo conhecer a totalidade da história, suas implicações e que tipo de abordagem terá a reportagem.

(...) o levantamento documental em torno do tema que está sendo investigado é uma das etapas mais importantes do processo de 
construção de uma reportagem investigativa. Tornar públicos fatos que grupos desejam esconder da sociedade exige necessariamente do repórter um conhecimento profundo sobre eles, que só um trabalho documental exaustivo e preciso poderá fornecer (Sequeira, 2005, p. 92).

Com o levantamento de todo material que encontra sobre o tema abordado para a produção de uma reportagem investigativa, outro processo importante no jornalismo investigativo é a rechecagem das informações, mesmo que elas não pareçam imprecisas ou inconsistentes. "Faz parte do bom jornalismo, sobretudo quando se trata de notícia sensível, abortar uma reportagem, por mais doloroso que seja, se ela tem falhas ou incongruências apresentadas na apuração" (Fortes, 2005, p.34).

Outro procedimento relevante na apuração jornalística investigativa é não se perder no acúmulo de informações e saber filtrar as que realmente correspondem à pauta investigada e não se perder no processo de investigação. De acordo com um levantado do Investigative Reporters and Editors (IRE) (apud Fortes, 2005, p.28), a quantidade de informações dobra a cada cinco anos, desde o final de década de 1990. "Esse quadro obrigou os jornalistas, sobretudo aqueles ligados à atividade investigativa, a criar métodos capazes de garantir uma seleção correta das informações, além de instrumentos racionais de avaliação, análise e comunicação" (Fortes, 2005, p.28).

\section{CONSIDERAÇÕES}

Este artigo buscou realizar uma discussão teórico conceitual sobre o jornalismo como objeto de pesquisa científica, considerando as peculiaridades e especificidades da produção jornalística investigativa. Propôs pensar um percurso metodológico de análise da mídia noticiosa nas produções investigativas, como forma de identificar quais são os métodos produtivos específicos do jornalismo investigativo, considerando um levantamento bibliográfico, aliado a entrevistas com profissionais da área e uma análise da produção jornalística investigativa.

Esse percurso metodológico foi pensado como estratégia que contempla as especificidades e características próprias do jornalismo. Com os dados obtidos ao final dessas três etapas do processo metodológico, a pesquisa espera 
aferir o conhecimento específico que norteia a prática do jornalismo investigativo e como se estabelece o diálogo entre teoria e prática no exercício desse gênero do jornalismo. A interpretação dos dados permitirá ainda encontrar um padrão na produção do jornalismo investigativo e a possível interferência das subjetividades dos profissionais na orientação de um protocolo de apuração.

A discussão faz parte de uma pesquisa de mestrado em andamento e traz algumas considerações preliminares com um padrão de técnicas e percurso na produção do jornalismo investigativo e onde há inferências das subjetividades dos jornalistas que atuam na área, ainda que haja um protocolo de apuração. Considera-se que as informações levantadas pela análise dos textos e pelas entrevistas têm relação direta com o processo de produção e produto final. Por isso, é possível que após conversar com mais profissionais, a análise seja retomada para avaliar outros aspectos. Com essas estratégias, a pesquisa quer mapear onde existem padrões no processo de produção do jornalismo investigativo e onde existem exceções, determinadas pela subjetividade dos profissionais.

\section{REFERÊNCIAS}

Arbex, D. (2012). Métodos de pesquisa e investigação. In R. Christofoletti \& S. Lima (orgs.) Reportagem, pesquisa e investigação. Florianópolis: Editora Insular.

Caria, T. H. (2005). Trajectória, papel e reflexividade profissionais: análise comparada e contextual do trabalho técnico-intelectual. In T. H. Caria (Org.). Saber profissional. Coimbra: Almedina.

Chaparro, C. (s.d.). De como a ciência pode ajudar a notícia. Revista PJ: $\mathrm{Br}$ (Jornalismo Brasileiro). São Paulo: ECA/USP, Edição 2. Disponível em: www2.eca.usp.br/pjbr/arquivos/forum2_a.htm. Recuperado em 20 de fevereiro de 2015.

Ettema, J. S. \& Glasser, T. L. (1984). On the epistemology of investigative journalism. Presented to the Qualitative Studies Division of the Association for Education in Journalism and Massi Communication, Gainesville, Florida, August. 
Fidalgo, J. (2008). Jornalistas e saberes profissionais. I Colóquio BrasilPortugal de Ciências da Comunicação - XXXI Congresso Brasileiro de Ciências da Comunicação.

Fortes, L. (2005). Jornalismo investigativo. São Paulo: Editora Contexto.

Genro Filho, A. (1987). O segredo da pirâmide - para uma teoria marxista do jornalismo. Porto Alegre: Ed. Tchê.

Gray, J; Bounegru, L. \& Chambers, L. (org) (2012). Manual de jornalismo de dados. Disponível em www.datajournalismhandbook.org/pt/ Acessado em 05 de março de 2016.

Groth, O. (2011). A tarefa da pesquisa científica sobre a cultura. In $O$ poder cultural desconhecido: fundamentos da ciência dos jornais. Petrópolis: Editora Vozes.

Hunter, M. L. (2013). A investigação a partir de histórias - um manual para jornalistas investigativos. Montevideo: Oficina Regional de Ciencias de la UNESCO para América Latina y el Caribe.

Kovach, B. \& Rosenstiel, T. (2004). Os elementos do jornalismo: o que os jornalistas devem saber e o público exigir. São Paulo, Geração Editorial.

Lopes, D. F. \& Proença, J. L. (2003). Jornalismo investigativo. São Paulo, Publisher Brasil.

Meditsch, E. (2008). O jornalismo como forma de conhecimento: uma abordagem qualitativa. In J. M. Melo, et al. Jornalismo, história, teoria e metodologia da pesquisa: perspectivas luso brasileiras (pp. 7-12). Porto: Universidade Fernando Pessoa.

Mendras, H. (1975). Princípios de sociologia: uma iniciação a análise sociológica. 4. ed. Rio de janeiro: Zahar.

Meyer, P. (1973). Precision journalism. Bloomington: Indiana University Press.

Nascimento, S. (2010). Os novos escribas: o fenômeno do jornalismo sobre investigações no Brasil. Porto Alegre, Arquipélago Editorial.

Oliveira JR, C. R. (orgs). (2012). Pesquisa em ciências sociais: interfaces, debates e metodologias (pp. 49-77). Ponta Grossa: Toda Palavra.

Pereira Jr, L. C. (2006). A apuração da notícia: métodos de investigação na imprensa. Petrópolis, Ed. Vozes. 
Rocha, P. M. (2015). Os impactos da tecnologia na produção jornalística e a formação do profissional. Artigo apresentado no XIV Congresso Internacional IBERCOM 2015, realizado em São Paulo no período de 29 de março a 2 de abril de 2015.

Schmitz, A. A. (2011). Fontes de notícias: ações e estratégias das fontes no jornalismo. Combook.

Sequeira, C. M. (2005). Jornalismo investigativo: o fato por trás da notícia. São Paulo: Ed. Summus.

Sobrinho, J. C. (2013). A essência do jornalismo está na apuração. In Moraes Júnior, et al. (org). Antes da pauta: linhas para pensar o ensino do jornalismo no século XXI. São Paulo: ECA.

Sousa, J. P. (2011). Elementos do jornalismo impresso. BOCC - Biblioteca On-Line de Ciências da Comunicação. Disponível em: http://www.bocc. ubi.pt/pag/sousa-jorge-pedro-elementos-de-jornalismo-impresso.pdf.

Sponholz, L. (2009). Jornalismo, conhecimento e objetividade: além do espelho e das construções. Florianópolis: Insular.

Walsh, R. (2010). Operação massacre. São Paulo, Companhia das Letras. 